\title{
SPLITTING FOR SURVIVAL - A CASE REPORT
}

\section{Dental Science}

Dr. Rahul Ravi*

P.G Student, Department of Prosthodontics, DY Patil University, School of Dentistry, Dr. Rubina Tabassum Navi Mumbai, India. *Corresponding Author

\section{Dr. Gaurang Mistry}

\section{Dr. Omkar Shetty}

\section{Dr. Adnan Kheyroolla}

Professor, Department of Prosthodontics, DY Patil University, School of Dentistry, Navi Mumbai, India.

HOD, Department of Prosthodontics, DY Patil University, School of Dentistry, Navi Mumbai, India.

Dean and Professor, Department of Prosthodontics, DY Patil University School of Dentistry, Navi Mumbai, India.

P.G Student, Department of Prosthodontics, DY Patil University School of Dentistry, Navi Mumbai, India.

\section{ABSTRACT}

Vertical root fractures of endodontically treated teeth are an exasperating complication that often leads to extraction of the tooth. Early detection and management of vertical root fractures, remain a vexing issue that has caused endless anguish for both the patient as well as the dental practitioner. Bicuspidization is a surgical procedure wherein the mesial and distal roots of primarily the mandibular molars are separated with their respective crown segments. This in turn helps the patient maintain effective oral hygiene by using an interdental brush, as it eliminates the presence of a furcation. This article elucidates the treatment procedure of a mandibular molar by biscuspidization.

\section{KEYWORDS}

Vertical root fractures, Bicuspidization, furcation, mandibular molar

\section{INTRODUCTION}

Recent advances in the field of dentistry have provided the patients a unique window of opportunity to retain a fully functional dentition for a lifetime. Therapeutic measures performed to ensure retention of teeth vary in complexity. The ensuing treatment would involve combining Prosthodontics, Endodontics, Orthodontics, and Periodontics so that the teeth are retained in whole or in part. ${ }^{[1,2,3]}$

The ideal treatment and long-term retention of mandibular molars with vertical root fractures or VRF's has always proved to be quite a challenge to the prosthodontist.

Vertical root fracture (VRF) is defined as a longitudinal fracture confined to the root that usually begins on the internal canal wall and extends outward to the root surface. ${ }^{[4]}$ VRF often goes unnoticed as there are no obvious presentation of signs and symptoms, leading to difficulty in diagnosis. Previous studies ${ }^{[5,6,7]}$ described the common clinical symptoms of VRF to be the presence of dull pain, swelling, and sinus tract, with a deep localized probing defect. The radiographic findings may show widening of the periodontal ligament and osseous resorptive defects. ${ }^{[8]}$

VRF usually occurs in endodontically treated teeth with or without post insertion. ${ }^{[9,10]}$

Bicuspidization involves modifying a single molar tooth into mesial and distal sections forming two bicuspids. The management of Grade III furcation defects in the mandibular molars is accomplished with root surface debridement, followed by open flap debridement with radisection, tunnelling procedures and, rarely, a regenerative approach. ${ }^{[4,10,11]}$

A Naber's probe is commonly used in the diagnosis as it passes through and through in the furcation area, despite the furcation not being clinically visible. ${ }^{[1,2,10,11]}$

\section{Indications for bicuspidization are following:}

1. Root fracture and severe bone loss affecting one or more roots untreatable with regenerative procedures

2. Class II or III furcation invasions or involvements

3. Inability to successfully treat and fill a canal

4. Severe root proximity insufficient for a proper embrasure space

5. Root trunk fracture or decay with invasion of the biological width

\section{Contraindications include the following:}

1. Poor oral hygiene

2. Fused roots

3. Unfavourable tissue architecture

4. Retained roots which are endodontically untreatable

This case report outlines a multidisciplinary treatment procedure for mandibular molar with grade III furcation involvement that comprises intentional root canal therapy, surgical periodontal therapy with bicuspidization and prosthodontic rehabilitation.

\section{CASE REPORT}

A 55-year-old male patient presented to the Department of Prosthodontics with the complaint of a cracked crown in the lower right quadrant. On examination, the right mandibular first molar (46) was debilitated and sensitive to percussion. On probing the area, there was a 5-mm-deep periodontal pocket around the furcation area (Fig.1). Vertical bone loss was seen on the intraoral periapical radiograph, though both the roots had fully intact bone support (Fig.2).

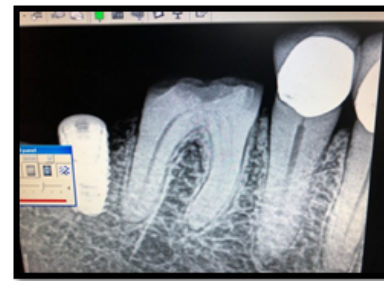

Fig.1: Pre-Operative Intraoral view

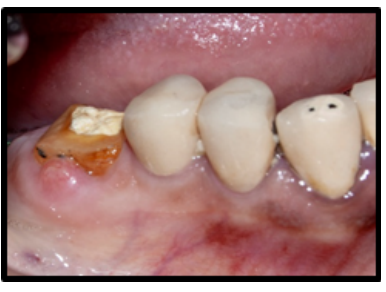

Fig.2: Pre-Operative Radiograph of 46
With the primary intention of saving the natural tooth, intentional root canal treatment of the mandibular right first molar was planned along with bicuspidization in this case. First, under local anesthesia, the access cavity was prepared and the working canal length was determined. The canals were biomechanically prepared using the stepback technique. Lateral condensation technique was used to obturate both the mesial and distal canals. A vertical cut method was used to separate the crown. A long shank straight fissure carbide bur was used to make a vertical cut extending to the bifurcation area. The single molar was now separated into two individual crowns. To remove any sharp surfaces created as a result of the sectioning, the furcation area was trimmed to ensure a smooth surface. Next, restorative debris was removed and curettage was done as the furcation area was now clearly 
accessible. Prefabricated metal posts were inserted, both in the mesial and distal canals after preparation of the post-space. The core for both individual crown sections were built up using core build-up composite material. The sections were then prepared and shaped as individual premolar crowns (Fig.3-6). Full Metal crowns were cemented on both these sections (Fig.7,8). The patient was called for a follow-up at 3,6,9 and 12 months after surgery, and clinical measurements and radiographs were recorded (Fig.9).

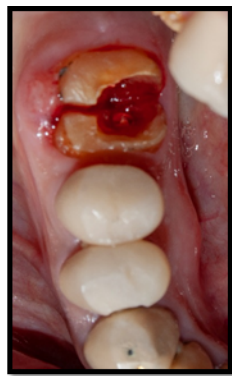

Fig.3: Tooth split buccolingually

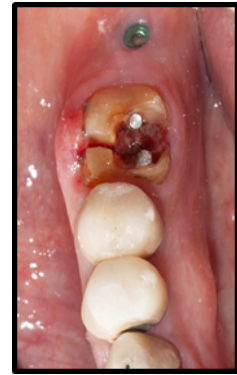

Fig.4: Posts cemented in root canals

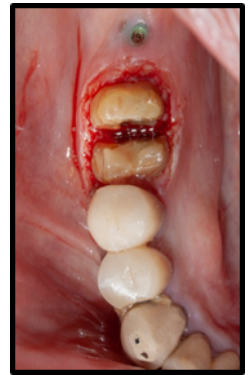

Fig.5: Core buildup and Tooth

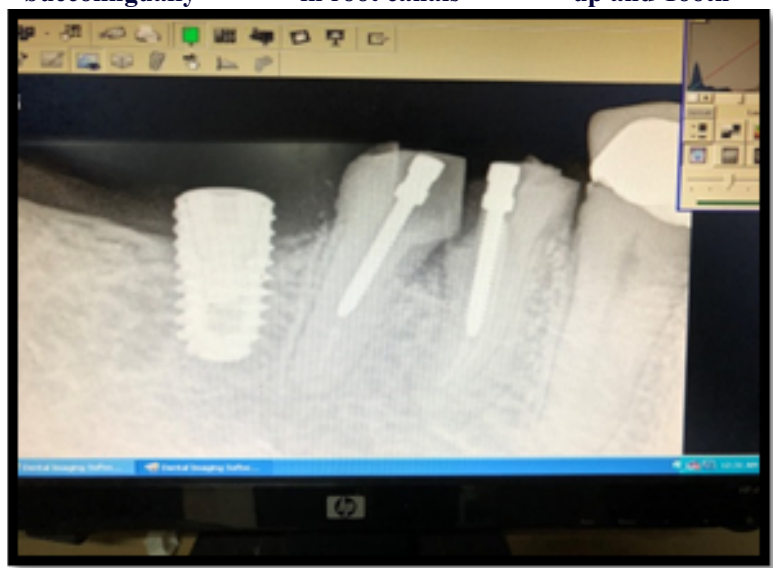

Fig.6: Intraoral Periapical Radiograph showing split roots with Post \& Core

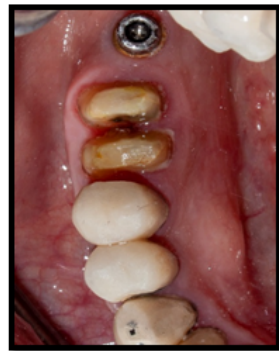

Fig.7: Tissue healing after 3 weeks

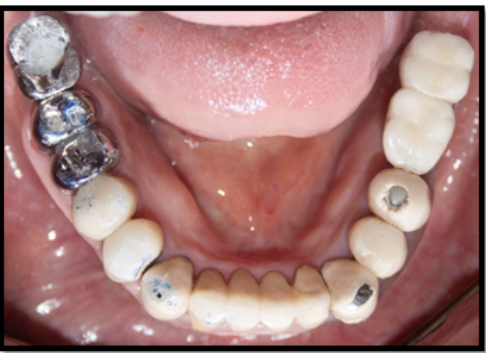

Fig.8: Final crowns cemented

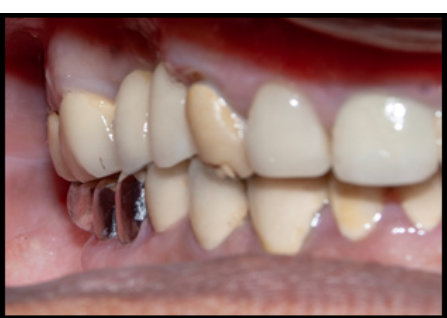

Fig.9: Final crowns

in occlusion

\section{DISCUSSION}

Most prosthodontists find managing advanced furcation involvement to be quite a daunting task. Non-surgical management alone leads to failure due to inaccessibility of the furcation region, leading to incomplete removal of plaque and plaque retentive factors. ${ }^{[4,5,12]} \mathrm{By}$ splitting the mandibular molar vertically through the furcation, simultaneously retaining both, the clinician creates two separate roots which are then treated as bicuspids. Farshchian and Kaiser ${ }^{[13]}$ have documented the success of a molar bisection with subsequent bicuspidization. They stated that the success of bicuspidization depends on three factors:

1. Stability and adequate bone support for the individual tooth sections

2. Absence of severe root fluting of the distal aspect of the mesial root or mesial aspect of the distal root

3. Adequate separation of the mesial and distal roots, to enable the creation of an acceptable embrasure for effective oral hygiene. According to Newell ${ }^{[14]}$ the merit of bisection is the retention of some or all the tooth structure and the disadvantage is that the tooth has to undergo endodontic therapy. However, in the present case report, the furcation-involved tooth 46 , had non-vital pulp and hence this technique seemed to be the most viable option. Not many studies have been cited in the literature regarding the use of bicuspidized molar teeth as a viable abutment for a fixed partial bridge.

With that being said, there are some drawbacks associated with bicuspidization. It might cause pain and anxiety, as would any surgical procedure. Endodontic therapy failure can also lead to the failure of this procedure. It is vital to relieve the tooth from lateral excursive forces and make sure there is proper adaptation at the margins. Failure to do so may lead to periodontal destruction. ${ }^{[1,16]}$

In this particular case, after bicuspidization of 46 , individual premolar crowns were prepared on separated roots and the prosthetic stage of the existing implant in the 47 region was planned. The occlusal contacts were reduced in size and favourably repositioned and the cuspal inclines were made less steep to reduce lateral forces. Case selection plays a truly important role in determining the long-term success of bicuspidization, which has a prognosis similar to everyday endodontic procedures. It is also vital that the restoration has an acceptable design in relation to the occlusal and periodontal needs of the patient. In this case bicuspidization was done to avoid the otherwise inevitable extraction of the 46 . The following appointments showed a good bone healing response, suggesting the treatment was ideal in aiding the recovery of the previously debilitated tooth. ${ }^{[17,18,19]}$

\section{CONCLUSION}

In most scenarios, mandibular molars with advanced furcation defects undergo eventual extraction. Bicuspidization is a promising conservative treatment alternative which aims to retain as much of the original tooth structure as possible. With recent advancements and fine-tuning in dentistry, root separation and resection have been widely embraced as a trustworthy treatment modality, with the teeth so being treated unfailingly enduring the demands of function.

\section{REFERENCES}

1] Walton, R.E. (1995). "Cracked tooth and vertical root fracture". In: Principles and practice of endodontics. 2nd ed. Philadelphia: WB Saunders; pp. 487-91.

[2] Pitts, D.L., and Natkin, E. (1983). "Diagnosis and treatment of vertical root fractures" Journal of Endodontics, 9(8):338-46.

[3] Testori, T., Badino, M. and Castagnola, M. (1993) "Vertical root fractures in endodontically treated teeth: a clinical survey of 36 cases". Journal of Endodontics, 19(2):87-91.

[4] Andreasen, F.M., Andreasen, J.O., and Cvek, M. (2007) "Root fractures. In: Textbook and Color Atlas of Traumatic Injuries to Teeth". Andreasen FM, Andreasen JO, edn. Copenhagen: Blackwell Publishing Ltd, pp. 337-371

[5] Flores, M.T., Andersson, L., Andreasen, J.O., Bakland, L.K., Malmgren, B., Barnett, F, Bourguignon, C., DiAngelis, A., Hicks, L., Sigurdsson, A., Trope, M., Tsukiboshi, M. and von Arx, T. Guidelines for fractured and luxated permanent teeth. Dental Traumatology, 23(3): 66-71

[6] Trope, M., Blanco, L., Chivian, N., and Sigurdsson, A. (2006), "Pathways of pulp". In: Role of Endodontics after Dental Traumatic Injuries. Cohen S, Hargreaves KM, eds. Missouri: Mosby, $610-649$.

[7] Grossmann, Y., Araúz-Dutari, J., Chogle, S.M., Blatz, M.B., and Sadan, A. (2006), "A conservative approach for the management of a crown-root fracture". Quintessence International, 37(10): 753-759.

[8] Tamse, A., Kaffe, I., Lustig, J., Ganor, Y., and Fuss, Z. (2006), "Radiographic features o vertically fractured endodontically treated mesial roots of mandibular molar". Oral Surgery, Oral Medicine, Oral Pathology, Oral Radiology, and Endodontics, 101(6):797-802.

[9] Joshi, T.J., Mistry, G., Shetty, D., Shetty, O., Singh, S., and Rumde, S. (2018). "A novel and easy technique for restoring grossly decayed mandibular molar with a modified castpost" Pan African Medical Journal, 31:129.

[10] Luebke, R.G. (1984). "Vertical crown-root fractures in posterior teeth". Dental Clinics of North America, 28(4):883-894.

[11] Schetritt, A., and Steffensen, B. (1995). "Diagnosis and management of vertical roo fractures". Journal of the Canadian Dental Association, 61(7): 607-613

[12] Rosen, H., and Partida-Rivera, M. (1986). "Iatrogenic fracture of roots reinforced with cervical collar". Operative Dentistry, 11(2): 46-50.

[13] Farshchian, F., and Kaiser, D.A. (1988). "Restoration of the split molar: bicuspidization". American Journal of Dentistry, 1(1):21-22.

[14] Newell, D.H. (1991). "The role of the prosthodontist in restoring root-resected molars: A 
study of 70 molar root resections". Journal of Prosthetic Dentistry, 65(1):7-15.

[15] Kurtzman, G.M., Silverstein, L.H., and Shatz, P.C. (2006). "Hemisection as an alternative treatment for vertically fractured mandibular molars". Compendium of alternative treatment for vertically fractured mandibular molars". Compendium of

[16] Tsesis, I., and Fuss, Z. (2006). "Diagnosis and treatment of accidental root perforations". Endodontic Topics. 13(1):95-107.

[17] Bohnenkamp, D.M., and Garcial, L.T. (2004). "Fixed restoration of sectioned mandibular molar teeth". Compendium of Continuing Education in Dentistry, 25(11):920-924.

[18] Kaur, J., Bala, S., and Sharma N. (2013). "Bicuspidization-restoration of split molara case report. Indian journal of applied research". 3(7):78-80.

[19] Shah, S., Modi, B., Desai, K., and Duseja, S. (2012). "Hemisection - A conservative approach for a periodontally compromised tooth - A Case Report". Journal of Advanced
Oral Research, 3(2):31-36. 